\title{
ERO1a promotes hypoxic tumor progression and is associated with poor prognosis in pancreatic cancer
}

\author{
Nikhil Gupta ${ }^{1}$, Jung Eun Park ${ }^{1}$, Wilford Tse $^{1}$, Jee Keem Low ${ }^{2}$, Oi Lian Kon ${ }^{3}$, Neil \\ McCarthy ${ }^{4}$ and Siu Kwan Sze ${ }^{1}$ \\ ${ }^{1}$ School of Biological Sciences, Nanyang Technological University, Singapore \\ ${ }^{2}$ Department of Surgery, Tan Tock Seng Hospital, Singapore \\ ${ }^{3}$ National Cancer Centre Singapore, Division of Medical Sciences, Singapore \\ ${ }^{4}$ Centre for Immunobiology, The Blizard Institute, Bart's and The London School of Medicine and Dentistry, Queen Mary \\ University of London, United Kingdom
}

Correspondence to: Siu Kwan Sze, email: sksze@ntu.edu.sg

Keywords: pancreatic cancer; hypoxia tumor; ERO la; SILAC; proteomics

Received: July 15, $2019 \quad$ Accepted: September 24, $2019 \quad$ Published: October 15, 2019

Copyright: Gupta et al. This is an open-access article distributed under the terms of the Creative Commons Attribution License 3.0 (CC BY 3.0), which permits unrestricted use, distribution, and reproduction in any medium, provided the original author and source are credited.

\section{ABSTRACT}

Pancreatic cancer is a leading cause of mortality worldwide due to the difficulty of detecting early-stage disease and our poor understanding of the mediators that drive progression of hypoxic solid tumors. We therefore used a heavy isotope 'pulse/trace' proteomic approach to determine how hypoxia (Hx) alters pancreatic tumor expression of proteins that confer treatment resistance, promote metastasis, and suppress host immunity. Using this method, we identified that hypoxia stress stimulates pancreatic cancer cells to rapidly translate proteins that enhance metastasis (NOTCH2, NCS1, CD151, NUSAP1), treatment resistance (ABCB6), immune suppression (NFIL3, WDR4), angiogenesis (ANGPT4, ERO1a, FOS), alter cell metabolic activity (HK2, ENO2), and mediate growth-promoting cytokine responses (CLK3, ANGPTL4). Database mining confirmed that elevated gene expression of these hypoxia-induced mediators is significantly associated with poor patient survival in various stages of pancreatic cancer. Among these proteins, the oxidoreductase enzyme ERO1a was highly sensitive to induction by hypoxia stress across a range of different pancreatic cancer cell lines and was associated with particularly poor prognosis in human patients. Consistent with these data, genetic deletion of ERO1a substantially reduced growth rates and colony formation by pancreatic cancer cells when assessed in a series of functional assays in vitro. Accordingly, when transferred into a mouse xenograft model, ERO1a-deficient tumor cells exhibited severe growth restriction and negligible disease progression in vivo. Together, these data indicate that ERO1a is potential prognostic biomarker and novel drug target for pancreatic cancer therapy.

\section{INTRODUCTION}

Pancreatic cancer is associated with $<10 \%$ patient survival within just 5 -years of diagnosis, reflecting a mortality rate approximately double that of other major cancer types [1-6]. Pancreatic Ductal Adenocarcinoma (PDA) is the most common form of pancreatic malignancy but is typically diagnosed only in late-stage disease, hence both the incidence and deaths attributable to PDA continue to increase [7,8]. At present, there is no clinical procedure that can accurately detect early asymptomatic PDA, largely due to the lack of specific biomarkers of disease $[9,10]$, hence there is an urgent need for better predictors of tumor development and progression in this patient group with extremely poor prognosis.

Hypoxia frequently affects solid tumors that outgrow their local supplies of oxygen and nutrients. Previous studies have reported that the average $\mathrm{pO}_{2}$ of a developing tumor is just $0-5.3 \mathrm{mmHg}$, whereas the $\mathrm{pO}_{2}$ of adjacent healthy tissues ranges between 9.2 and 
$92.7 \mathrm{mmHg}$ [11], indicating that hypoxia is a major influence on the biology of developing cancers. In particular, hypoxia-inducible factor (HIF-1 $\alpha$ ) is a key regulator of cellular responses to low-oxygen stress and appears to play a critical role in mediating tumor survival and rate of progression [12-15]. In part, this is achieved via HIF- $1 \alpha$ induction of pro-angiogenic mediators such as vascular endothelial growth factor (VEGF) [16-18], and transcription factors including Twist, Snail, and ZEB1 that promote epithelial-mesenchymal transition (EMT) $[19,20]$. Together, these effects significantly enhance neo-vascularisation of the tumor site, promote tissue invasion/metastasis, and increase chemotherapy resistance in many epithelial cancers. In pancreatic tumors, HIF-1 $\alpha$ expression in a $\mathrm{CD} 133$ + stem cell-like population has been shown to promote EMT [21], and mutations in HIF-1 $\alpha$ itself are key drivers of a variety of cancer types including PDA [22]. These data are consistent with the emerging consensus that hypoxia-induced metabolic reprogramming is a hallmark feature of solid tumors including PDA [23], and acts as a key driver of epigenetic changes that promote early invasion and metastasis [24-26], in addition to promoting immunosuppressive phenotypes that limit the effectiveness of many cancer therapies [27, 28]. Despite substantial research progress, the molecular mechanisms that underpin hypoxia-induced effects on tumor development remain poorly understood, hence pancreatic cancer prognosis has failed to improve significantly for many years and treatment options for this disease remain extremely limited.

In the current study, we sought to determine the molecular basis of hypoxia effects on pancreatic cancer progression by using a pSILAC proteomic method (pulsed Stable Isotope Labelling of Amino acid in Cell culture) which facilitates analysis of how environmental factors impact on de novo protein synthesis via LC-MS/MS-based quantitation [29, 30]. Using this approach, we investigated how the repertoire of proteins being actively translated by PDA cells is modified by nutrient starvation and hypoxia stresses, before then comparing these data with patient survival statistics and pancreatic cancer gene expression profiles in publically available databases (PRECOG and GEO). These analyses revealed that the oxidoreductase enzyme ERO1 $\alpha$ is actively translated by PDA tumors under both hypoxic and serum-free conditions, while also constituting a highly expressed gene associated with poor patient survival in both PRECOG and GEO datasets. Accordingly, genetic deletion of ERO1 $\alpha$ inhibited pancreatic tumor proliferation, colony formation, and cellular ROS production in vitro, while cell transfer into a mouse xenograft model confirmed a profound reduction in tumor development in vivo. Together, these data indicate that hypoxia-induced enzyme ERO1 $\alpha$ is a novel therapeutic target in pancreatic cancer and a potential biomarker for enabling earlier disease detection and better prediction of clinical course in human patients.

\section{RESULTS}

\section{Hypoxia induces dynamic changes in pancreatic cancer cell translational activity}

The molecular mechanisms by which hypoxia favors pancreatic cancer progression and therapy resistance remain poorly understood. We hypothesized that hypoxic cancer cells co-opt normal metabolic pathways to force translation of proteins that support growth in unfavorable local conditions. To test this concept, we used a pSILAC proteomic approach to investigate how the pancreatic tumor cell proteome is modified in response to a hypoxic microenvironment. To mimic tumor hypoxia in vivo, we first cultured pancreatic ductal adenocarcinoma (PDA) cells under low-oxygen conditions in vitro, either in the presence or absence of serum, and then compared viability with cells maintained on normal oxygenation (normoxia; $\mathrm{Nx}$ ) throughout. When assessed in MTT assays, PDA cells displayed stable growth rates over a $24 \mathrm{~h}$ culture period irrespective of serum supplementation, and cell viability remained essentially unchanged thereafter. In contrast, PDA cells subjected to low-oxygen conditions displayed reduced proliferation after just $24 \mathrm{~h}$ culture (Figure 1A), while substantially upregulating the characteristic hypoxia markers HIF-1 $\alpha$, hexokinase 2 (HK2) and N-Myc Downregulated protein 1 (NDRG1) (Figure 1B). These data confirmed that our model system reproduces the oxygen-deprived state encountered by solid pancreatic tumors in vivo and replicates their associated cellular responses in vitro [31,32]. We therefore proceeded to culture PDA cells with light-medium $\left({ }^{12} \mathrm{C}_{6},{ }^{14} \mathrm{~N}_{2}\right.$-LLysine, ${ }^{12} \mathrm{C}_{6},{ }^{14} \mathrm{~N}_{2}$-L-Arginine) before switching to heavy medium $\left({ }^{13} \mathrm{C}_{6},{ }^{15} \mathrm{~N}_{2}\right.$-D-Lysine, ${ }^{13} \mathrm{C}_{6},{ }^{15} \mathrm{~N}_{2}$-D-Arginine $)$ and subjecting the cells to $24 \mathrm{~h}$ culture under normoxia $(\mathrm{Nx})$ or hypoxia $(\mathrm{Hx})$ in the presence or absence of serum. Upon completion of culture, cellular proteins were extracted and analysed by LC-MS/MS in order to identify molecules that incorporated heavy isotope-labelled Lys and Arg (synthesized de novo in response to hypoxia stress) and differentiate these from 'light' proteins derived from the pre-existing pool within the tumor cells ( $n=2$ biological replicates; Supplementary Data 1). Adjusted $p$ values were generated by PD 2.2 software analysis of the pSILAC data. We observed that PDA cells expressed a wide range of different proteins after culture, whether conducted in normoxia under serum replete (5684) or serum-free conditions (5944), or following hypoxia with serum provided (5932), or withheld for the duration (5677) (Figure 1C). Unsurprisingly, the majority of these proteins were derived from a common pool of shared molecules $(n=5010)$, but a substantial fraction were specifically modulated in response to changing microenvironmental conditions (threshold $>0.6 \quad \log _{2}$ Fold Change in H/L ratio) (Figure 1D). These candidate 
mediators of the tumor response to hypoxia stress were subsequently screened and cross-validated by RT-qPCR and western blot in order to verify the pSILAC results. Distribution analyses revealed that most of these proteins were substantially downregulated during hypoxia stress, regardless of serum provision, including several key mediators of cell translation, metabolism, and mRNA maturation processes (Supplementary Figure 1).

Among the proteins induced by pancreatic tumor hypoxia (high $\mathrm{Hx} / \mathrm{Nx}$ ratios), we observed that 206 were actively synthesized under serum-free conditions, 138 were translated in the presence of serum, and 20 were actively expressed in both conditions (Figure 2A). Comparisons between these groups based on functional classification revealed that the majority of hypoxiasensitive proteins were mediators of signaling pathways/ communication and cell growth, but we also detected marked hypoxia effects on key regulators of protein and nucleic acid metabolism. Several proteins already known to promote tumor metastasis (NOTCH2, NCS1, NUSAP1, CD151), were increased more than 10-fold under hypoxic conditions, further demonstrating the potent effects of oxygen restriction on cancer cell biology. In addition, we observed that hypoxic culture stimulated tumor cell upregulation of multiple proteins that have previously been implicated in host immune suppression (NFIL3, WDR4) and tumor drug resistance (ABCB6), suggesting that these mediators may contribute to poor survival rates among PDA patients.

Further analysis indicated that several critical mediators of cellular transport and metabolic activity were more potently induced by hypoxia under serumfree conditions (Figure 2B and Supplementary Figure 2 and Supplementary Data 2), indicating that nutrient availability plays a major role in determining how oxygen restriction modifies pancreatic tumor biology. Among the 20 proteins induced by hypoxia irrespective of serum presence/absence were several well-established mediators of cancer progression, including key oncogenic transcription factors FOS and JUN, as well as the proangiogenic factor ANGPTL4 which is directly involved in neo-vascularization events (Figure 2C). Several other proteins in this group also displayed greater induction under serum-free conditions (NOL3, NCS1, CD151), suggesting synergistic effects of hypoxia and nutrient deprivation on pancreatic cancer cell development and angiogenic activity (Figure 2D). To confirm these findings, gene expression levels were validated by quantitative PCR analyses, which were highly consistent with the pSILAC proteomic data (see Supplementary Figure 2). Having identified a range of hypoxia-induced proteins that are expressed by pancreatic cancer cells in vitro, it remained unclear which of these mediators exerted the greatest impact on malignant disease progression in vivo.

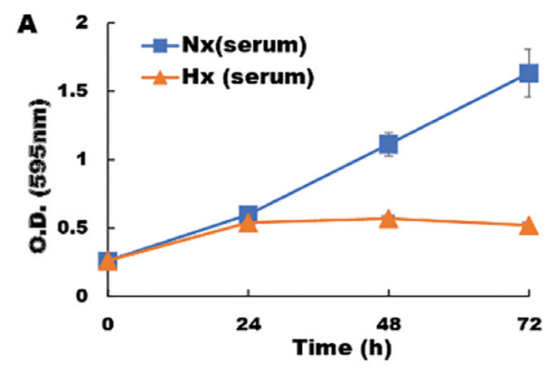

C

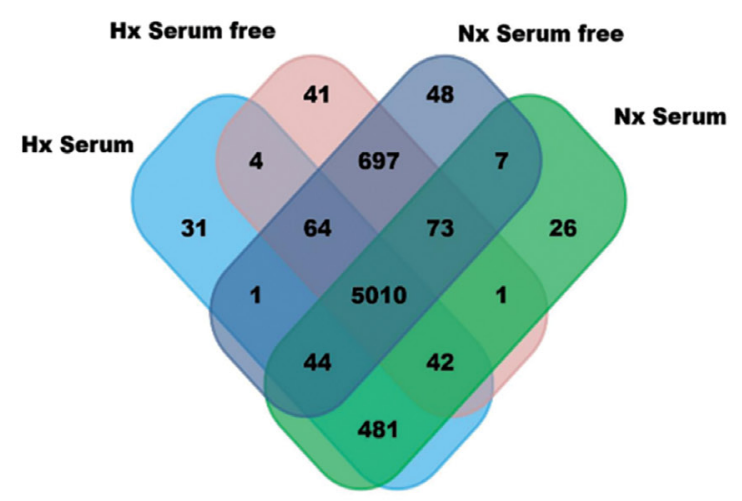

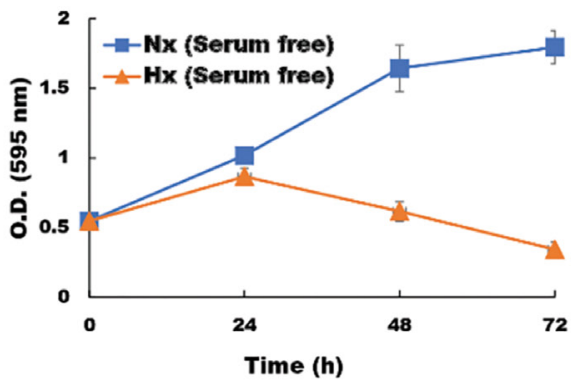
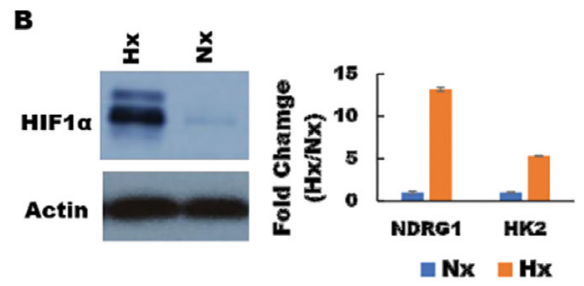

D

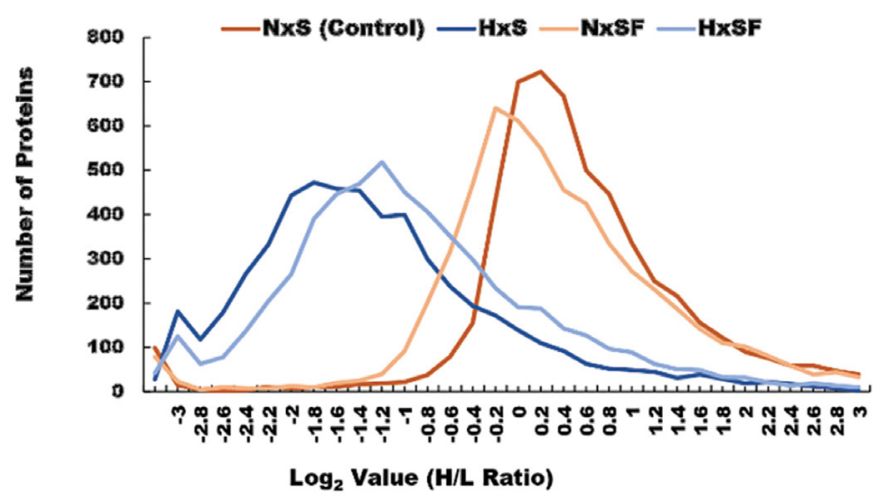

Figure 1: Hypoxia modifies the pancreatic cancer cell proteome under both serum-replete (S) and serum-free conditions (SF). (A) PDA cell proliferation curve during culture in S and SF conditions confirming growth restriction during hypoxia. (B) Western blot of HIF-1 $\alpha$ protein and RT-PCR assessment of fold change $(\mathrm{Hx} / \mathrm{Nx})$ in hypoxia markers NDRG1 and HK2. (C) the number of proteins identified in PDA cells after culture under the different conditions indicated. (D) Analysis of protein distribution against $\log _{2} \mathrm{H} / \mathrm{L} \mathrm{ratio} \mathrm{for}$ the $\mathrm{S}$ and SF culture conditions during normoxia/hypoxia revealed that the majority of these proteins are downregulated during hypoxia. Nx, normoxia; Hx, hypoxia; S, serum/serum replete; SF, serum-free; H/L, heavy/light chain ratio. 
We therefore proceeded to investigate whether hypoxiainduced changes in pancreatic cancer cell proteome impact on disease progression and modify patient outcome using real-world clinical data.

\section{Oxygen restriction induces pancreatic cancer cell expression of metabolic mediators that predict poor clinical outcome}

To determine the clinical relevance of hypoxiainduced changes in protein expression by PDA cells, we conducted 'PREdiction of clinical outcome from genomic profiles' (PRECOG) analysis to identify possible correlations of our proteomic results with patient survival data. [28] Hypoxia-induced proteins were first integrated into PRECOG and meta $\mathrm{z}$ scores calculated to determine the confidence level of associations with adverse or favorable clinical outcomes (Figure 3A). Using this approach, we observed that several proteins associated with poor prognosis were more strongly induced by hypoxia during serum starvation (Figure $3 \mathrm{~B}$ ) and that meta $\mathrm{z}$ scores for the pancreatic cancer dataset were generally higher in serum-free relative to serum-replete conditions. Among these were several proteins for which high gene expression levels were strongly associated with poor patient prognosis, suggesting a likely role in hypoxia-driven PDA progression. In particular, the

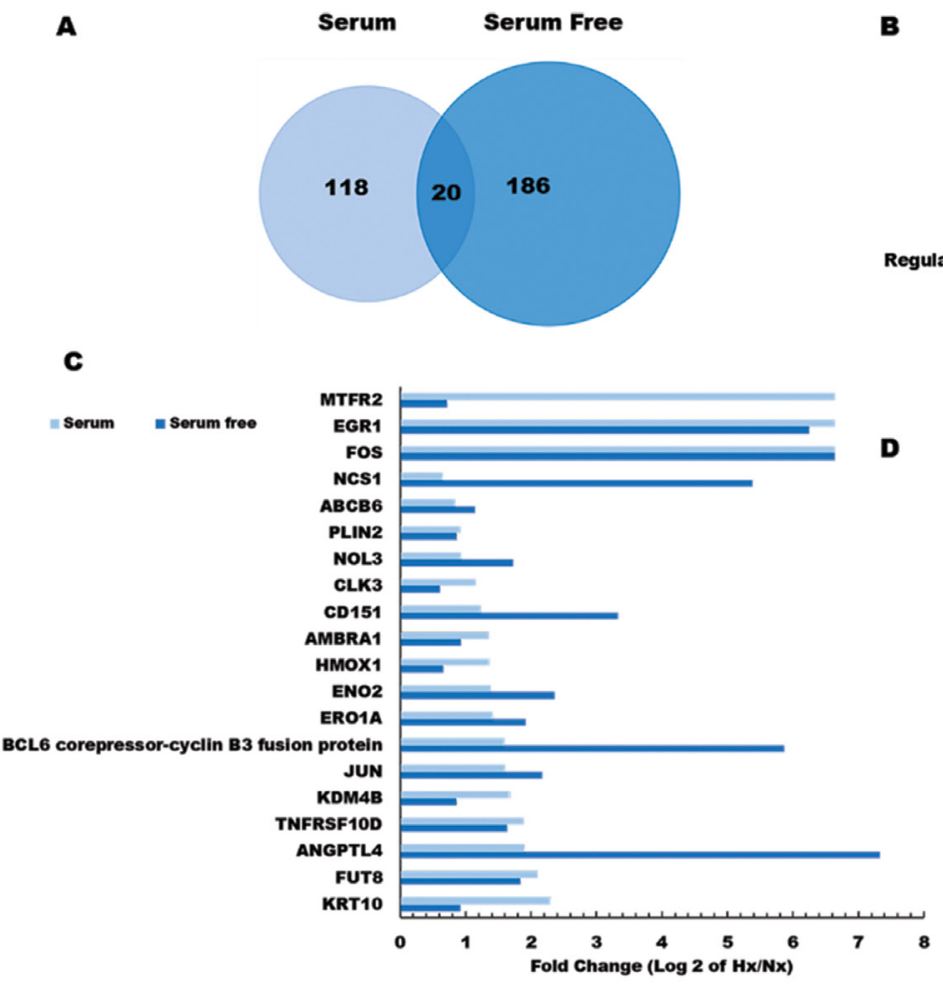

oxidoreductase protein ERO1 $\alpha$ displayed an unweighted meta $\mathrm{z}$ score of 7.67 for all cancer types, thus strongly implicating this enzyme as a key determinant of poor clinical outcome in human pancreatic cancer. These data were then verified by qRT-PCR and western blot analyses in both human MIAPaCa-2 and mouse TGP47 pancreatic cancer cells, which confirmed that PDA cells express ERO1 $\alpha$ at levels consistent with our proteomic results (Figure 4A and 4B and Supplementary Figure 3). Indeed, further analysis of ERO1 $\alpha$ expression patterns in relevant GEO databases, [33] enabled us to confirm that a range of different pancreatic cancer cell lines strongly upregulate ERO1 $\alpha$ under hypoxic conditions (Figure 3F). Mining of additional publicly available datasets (Supplementary Table 2) revealed that this enzyme is also expressed at significantly higher levels in pancreatic tumor samples compared with adjacent healthy tissue (Figure 3C and 3D), in clear association with adverse patient outcomes (Figure 3E). Together, these data strongly indicate that under hypoxic conditions, pancreatic tumor cells significantly upregulate the enzyme ERO1 $\alpha$, which is a critical determinant of pancreatic cancer patient survival. While ERO1 $\alpha$ plays a well-established role mediating disulfide bond formation in a range of different secreted and membrane proteins, the survival advantages this confers on PDA cells and the mechanisms involved remained unknown.
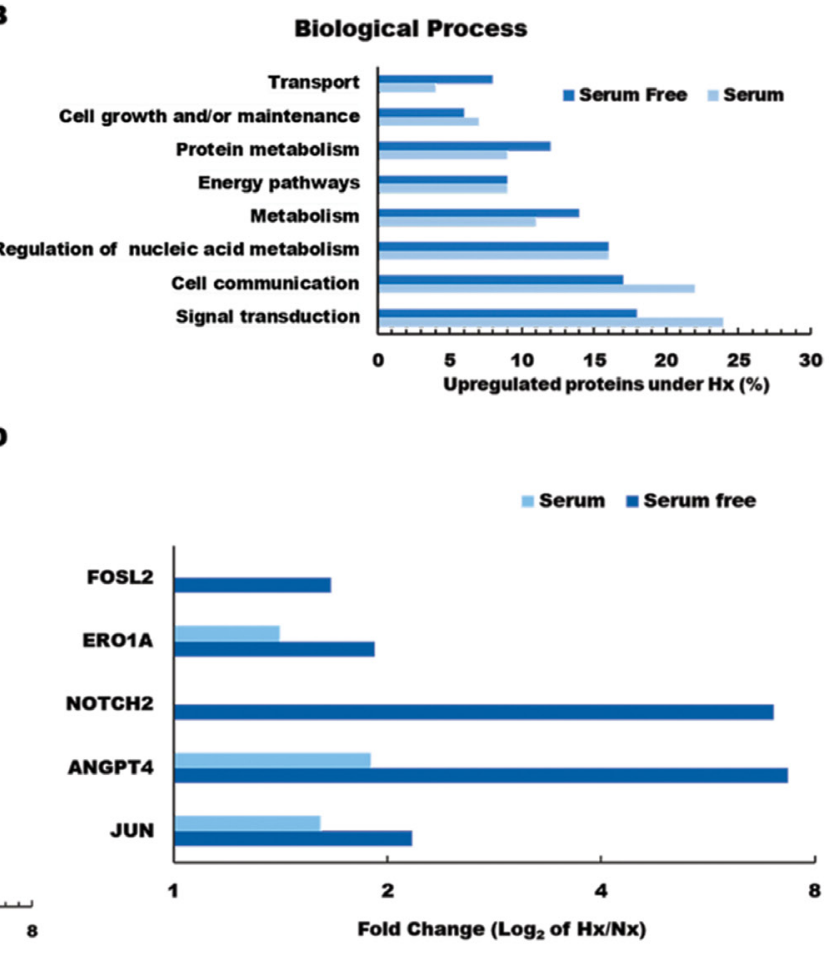

Figure 2: Gene ontology analysis of hypoxia effects on the pancreatic tumor cell proteome. (A) Venn diagram showing the number of hypoxia-induced proteins identified as being newly synthesized under S or SF conditions. (B) Functional classification of tumor proteins expressed de novo in response to hypoxia stress. (C) $\log _{2}$ fold change $(\mathrm{Hx} / \mathrm{Nx})$ in actively translating proteins detected in either $\mathrm{S}$ or SF culture conditions, and (D) $\log _{2}$ fold change $(\mathrm{Hx} / \mathrm{Nx})$ in angiogenic factor expression comparing $\mathrm{S}$ and $\mathrm{SF}$ culture conditions. $\mathrm{Nx}$, normoxia; Hx, hypoxia; $\mathrm{S}$, serum/serum replete; SF, serum-free; H/L, heavy/light chain ratio. 
ERO1 $\alpha$ mediates pancreatic cancer cell growth, ROS production, and tumorigenicity in vivo

To better understand the role of ERO1 $\alpha$ in pancreatic cancer progression, we next deleted the corresponding gene using CRISPR/Cas genome editing technology and assessed the impact on tumor cell function both in vitro and in vivo. For this, we selected a sgRNA with the highest 'on target' score, which was directed against exon 7 of human ERO1 $\alpha$ and predicted to induce a frameshift mutation that generates non-functional/truncated gene products. We then infected human pancreatic cancer cells with Cas9-expressing lentiviral vectors in order to disrupt the ERO1 $\alpha$ gene and used Sanger sequencing to verify mutation at the predicted site. Accordingly, western blot analysis of ERO1 $\alpha$ expression in the treated cells confirmed that our gene disruption strategy achieved complete knockout of ERO1 $\alpha$ protein (Figure 4C), so we proceeded to test whether pancreatic tumor cell proliferation rates differed between WT and ERO1 $\alpha-\mathrm{KO}$ clones. Unlike their WT counterparts, ERO1 $\alpha$-KO tumors displayed little to no growth over a 24-72 h culture period (Figure 4F), and colony formation was reduced by as much as 50\% (Figure 4D and 4E), suggesting that ERO1 $\alpha$ deletion significantly reduces the replicative capacity of pancreatic cancer cells. Furthermore, when assessed in a series of wound healing assays, we observed that ERO1 $\alpha$ KO tumor cells displayed impaired ability to close the injury due to migration rates being reduced by half relative to ERO1 $\alpha$-competent tumor cells (Figure 4G). Given these marked defects in cell motility, we next assessed tumor cell expression of cadherins, which play a central role in restricting cancer cell migration and tissue invasion. When analyzed by western blot, key EMT suppressor E-cadherin was found to be highly expressed in ERO1 $\alpha$-KO tumor cells, perhaps explaining their reduced migratory potential in our functional assays (Figure $4 \mathrm{H}$ ).

Having detected a clear impact of ERO1 $\alpha$ deletion on PDA cell expression of a key protein regulator of tumor development, we next investigated whether ERO1 $\alpha$ was also required to induce other critical mediators of disease progression. In particular, HIF- $1 \alpha$ is a critical regulator of many oncogenic pathways known to be triggered by hypoxia, and our western blot analyses revealed a significant deficit in expression of this transcription factor in ERO1 $\alpha-\mathrm{KO}$ cells (Figure 5A) [34]. Furthermore, in the absence of ERO1 $\alpha$, we observed that PDA cells also displayed substantially reduced expression of the immune

A

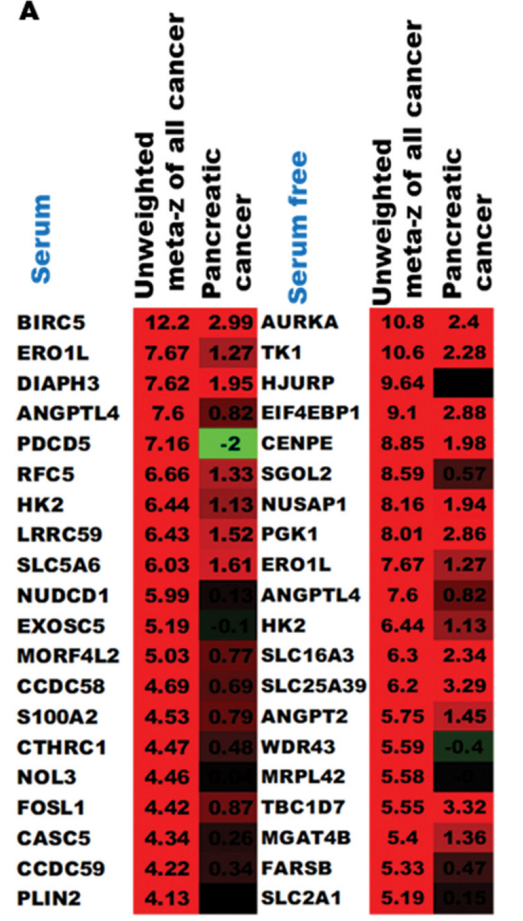

C

D
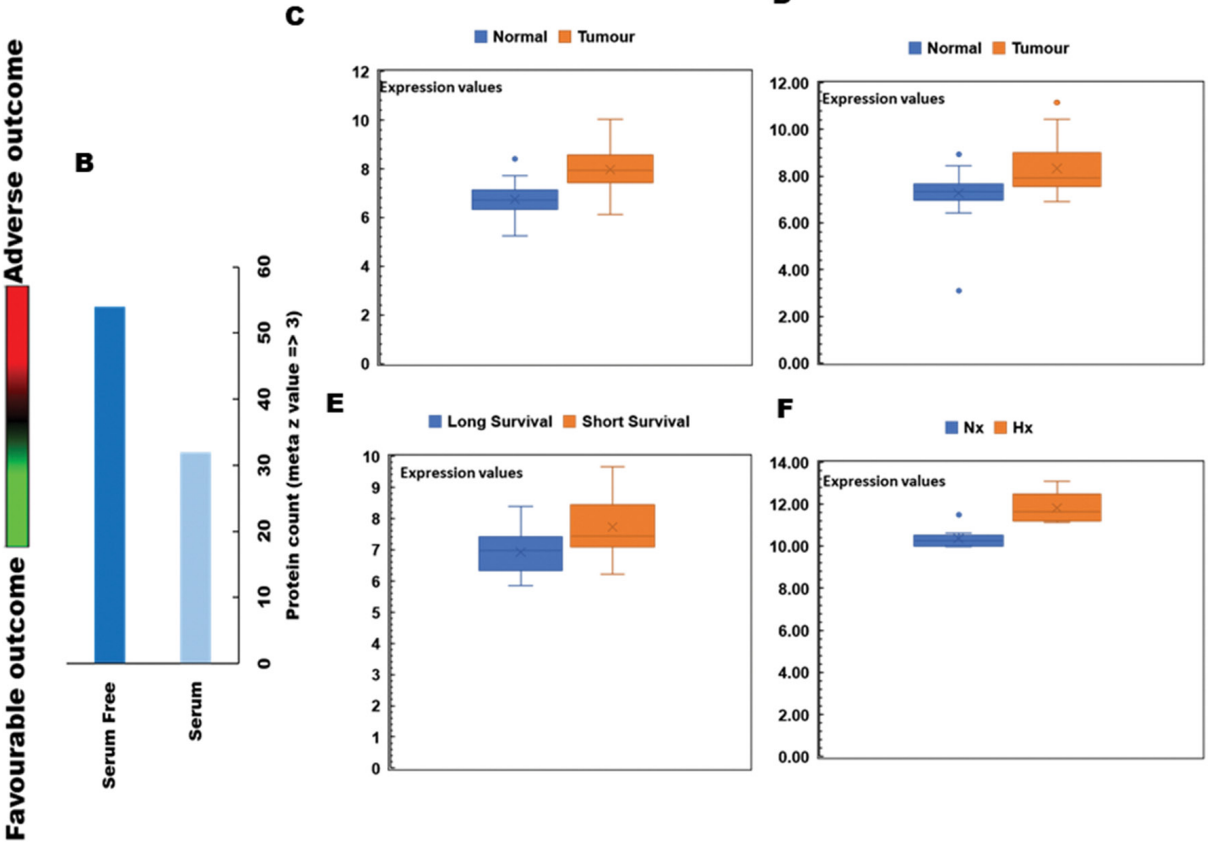

Figure 3: PRECOG analysis of the pancreatic tumor proteome and correlations with patient outcomes. (A) Top 20 genes associated with poor clinical prognosis in cancer patients and identified in our pSILAC dataset of hypoxia-induced proteins (high meta $z$ values indicating proteins most strongly associated with adverse [red] or favourable [green] survival data) (B) Protein count in serumreplete $(\mathrm{S})$ and serum-free $(\mathrm{SF})$ conditions, indicating that markers associated with poor prognosis are more strongly induced by hypoxia (meta $z$ value $>3$ ) during SF culture. (C) Comparison of ERO1 $\alpha$ expression levels between healthy tissues and disease samples in relevant GEO datasets: GSE28735; 45 pancreatic tumor samples and 45 matching normal samples (D) GSE15471; 78 pancreatic cancer and normal tissue samples (E) GSE78229; 50 pancreatic tissue samples grouped by survival duration, and (F) GSE67549; $n=9$ pancreatic cancer cell lines either cultured in Nx or subjected to Hx. Database selection criteria are displayed together with an overview of the 4 studies selected in Supplementary Table 2. Nx, normoxia; Hx, hypoxia; S, serum/serum replete; SF, serum-free; H/L, heavy/light chain ratio. 
inhibitory molecule PD-L1, which is typically upregulated in many different cancer types (Figure 5A). Given that HIF-1 $\alpha$ expression is known to be controlled by reactive oxygen species (ROS), we next assessed whether the generation of these mediators might represent an important mechanism by which ERO1 $\alpha$ influences pancreatic cancer progression. Indeed, previous work has identified that ERO1 $\alpha$ oxidizes PDI which in-turn catalyzes the formation of disulfide bonds in folding proteins, while simultaneously generating intracellular hydrogen peroxide $\left(\mathrm{H}_{2} \mathrm{O}_{2}\right)$ that can mutate DNA and trigger oncogenic events. When assessed in fluorescence-based DCDFA assays, we observed that PDA cells lacking ERO1 $\alpha$ displayed substantially reduced ability to generate ROS, exhibiting only $66 \%$ of the ROS capacity detected in WT tumor cells (Figure 5B and 5C). Together, these data confirmed that ERO1 $\alpha$-deficient PDA cells exhibit impaired tumor development in vitro, so we next performed xenograft experiments in Ncr-nude mice to determine whether these cells also displayed reduced oncogenic potential in vivo. When administered by subcutaneous (s.c) injection, ERO1 $\alpha$-competent tumors developed readily within just 2 weeks of cell transfer, whereas ERO1 $\alpha$-deficient cancer cells failed to drive tumor formation in recipient animals
( $n=6$ per group). Indeed, when skin was excised from the injection sites we were unable to detect significant tumor development in any mice that had received ERO1 $\alpha-\mathrm{KO}$ PDA cells (Figure 5D and 5E). These data confirm that in the absence of ERO1 $\alpha$, pancreatic tumor cells undergo regression rather than progression in vivo.

\section{DISCUSSION}

Low oxygen availability in solid tumors is now well established as a crucial factor driving malignant progression, promoting treatment resistance, and conferring poor clinical outcome in pancreatic cancer. [35] Since the molecular basis of these effects remains poorly defined, we used a pSILAC proteomic approach to identify hypoxia-sensitive proteins expressed by pancreatic cancer cells when subjected to oxygen restriction in vitro either in the presence or absence of serum supplementation (mimicking restricted blood/nutrient supply in vivo). Using this model, we detected rapid induction of several established biomarkers of tumor hypoxia and observed that active protein translation was broadly downregulated in the oxygen-deprived microenvironment. However, we also identified that hypoxic stress induces pancreatic tumor cell
A

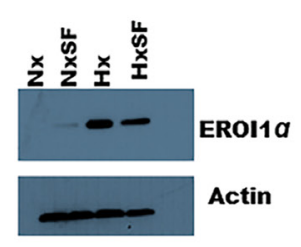

D

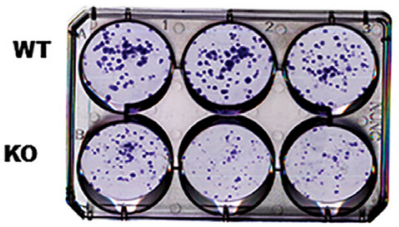

E

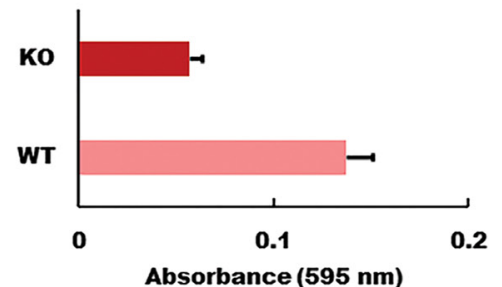

B ERO1a (m-RNA expression)

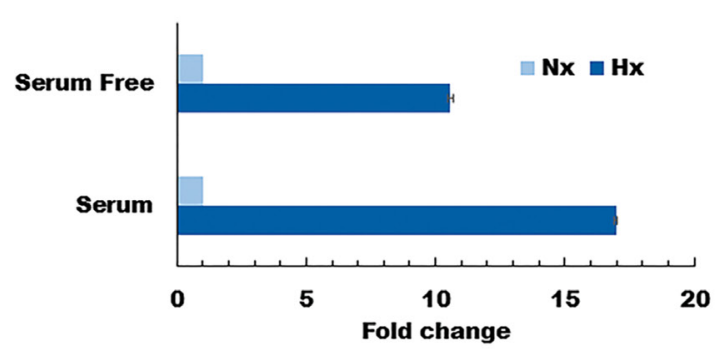

$\mathbf{F}$

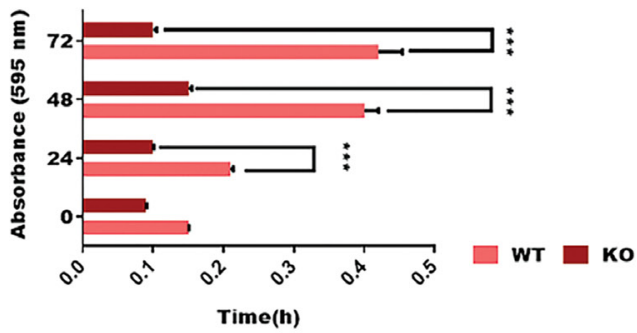

C
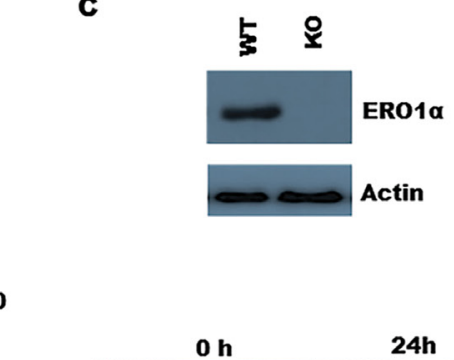

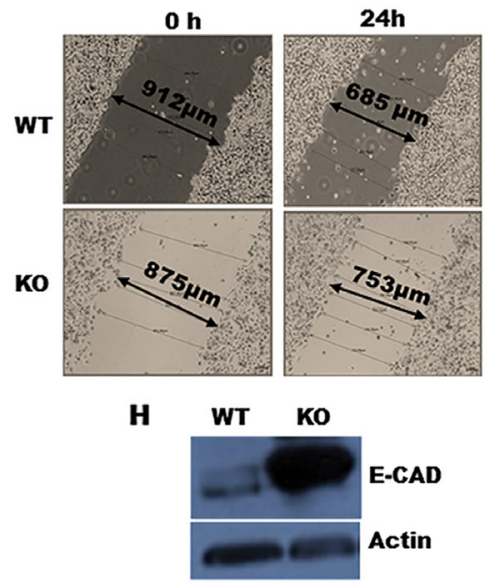

Figure 4: ERO1a deletion reduces PDA tumor cell growth, colony formation, and migratory potential in vitro. (A) Western blot confirming that ERO1 $\alpha$ protein is highly expressed during tumor hypoxia in both S and SF conditions, consistent with the pSILAC data and patient gene expression profiles in the PRECOG and GEO datasets. (B) ERO1 $\alpha$ mRNA expression levels as assessed using qPCR. (C) Western blot analysis of ERO1 $\alpha$ expression in WT and ERO1 $\alpha$-KO PDA cells. (D, E) Colony formation potential of PDA cells comparing WT and ERO1 $\alpha$-KO clones. (F) Cell proliferation curves of WT and ERO1 $\alpha$-KO clones in hypoxic MTT assays. (G) Wound-healing assay performed using the indicated cell clones and culture conditions, demonstrating the reduced migratory potential of ERO1 $\alpha$-KO tumor cells. (H) Western blot analysis of the archetypal EMT suppressor protein E-cadherin, which was overexpressed in ERO1 $\alpha$-KO PDA cells. ${ }^{* * *} P<0.001$. Nx, normoxia; Hx, hypoxia; S, serum/serum replete; SF, serum-free; NxSF, normoxia serum-free; HxSF, hypoxia serum-free; H/L, heavy/light chain ratio; WT, wild type; KO, knockout (ERO1 $\left.\alpha^{--}\right)$. 
expression of the oxidoreductase enzyme ERO1 $\alpha$, which displayed a clear association with poor survival statistics mined from patient gene expression databases.

Hypoxia is known to impede the growth of both tumors and healthy cell types, but variable severity and duration of hypoxia can induce a range of different effects that have been shown to increase cancer cell viability, therapy resistance, and metastatic potential [34, 36, 37]. While tumor translational activity was generally downregulated during low-oxygen stress in our assays, we also detected a group of proteins that were instead selectively induced by hypoxia (206 in serum-free cultures, 138 under serum-replete conditions, and 20 that were actively synthesized in both settings). The relatively high number of tumor proteins upregulated in serumfree culture might indicate translation of molecules that support cancer cell survival under adverse conditions. In support of this concept, the profile of proteins induced in the presence/absence of serum displayed divergent functional profiles, with serum-replete culture favoring mediators of cell communication and signal transduction, whereas serum-free conditions induced regulators of cellular transport and metabolic processes. Hypoxia stress also induced several proteins that have been shown to increase metastasis, promote immune suppression, and enhance treatment resistance in multiple different cancers.
One such highly-upregulated $(\mathrm{Hx} / \mathrm{Nx}>10)$ molecule in our dataset was the calcium-binding protein NCS1 (neuronal calcium sensor 1) which performs a variety of different functions in normal cell biology but has also been shown to promote metastasis in breast cancer. [38] Furthermore, our data indicated that hypoxic tumors subjected to serum starvation displayed greater induction of the anti-apoptotic protein NOL3, key mediator of tumor migration/invasion CD151, and angiogenic factor ANGPTL4 which supports tumor neovascularization. Together, these data indicate that hypoxia effects on pancreatic tumor development are strongly influenced by the nutrient status of the constituent cancer cells, which subsequently upregulate key mediators of cell survival, dissemination, and angiogenic processes.

In order to determine the clinical relevance of hypoxia-induced protein translational activity in pancreatic cancer cells, we integrated our data with cancer patient survival statistics available via public gene expression databases. Using the 'PRECOG' tool to identify associations between gene expression levels and clinical outcomes, we were able to identify which hypoxiatriggered proteins exert the greatest influence on cancer patient prognosis. Intriguingly, proteins associated with poor prognosis were more actively translated by hypoxic tumors in serum-free cultures than in serum-replete conditions, further indicating that nutrient availability
A

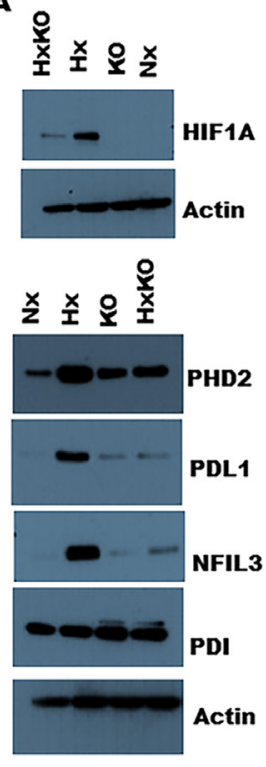

$\mathbf{B}$

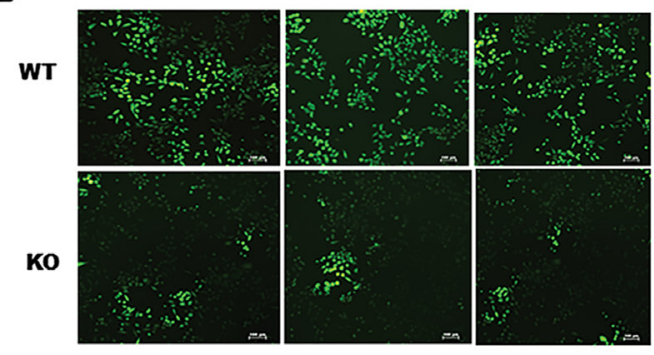

D

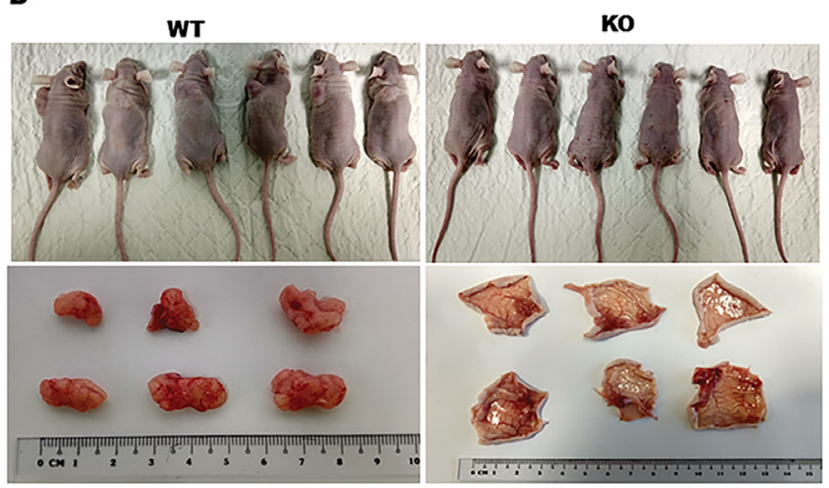

C

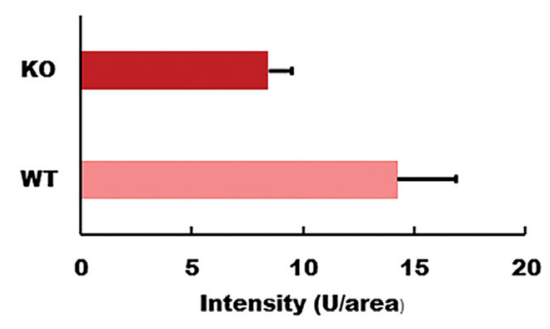

E

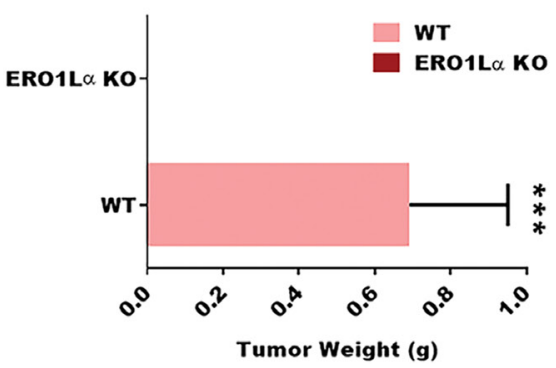

Figure 5: Impact of ERO1a deletion on oncogenic protein expression, ROS production, and xenograft tumor progression in vivo. (A) Western blot analysis of ERO1 $\alpha$-regulated proteins comparing WT with ERO1 $\alpha$-KO tumor cells. (B) DCFDA assay with representative fluorescence images of WT and ERO1 $\alpha-\mathrm{KO}$ PDA cells showing a significant reduction in ROS generation in ERO1 $\alpha$-deficient tumors. (C) Fluorescence intensity was measured by microplate reader confirming significant ROS impairment in ERO1 $\alpha$ KO clones (D) Representative images of xenografted mouse tumor injection sites before and 28 days after inoculation with the indicated cancer cells. (E) Tumors were excised and weighed; (mean \pm s.d., $n=6 /$ group. ${ }^{* * *} P<.001$ (student $t$-test). WT, wild type; Hx, hypoxia; $\mathrm{KO}$, knockout (ERO1 $\left.\alpha^{--}\right)$; HXKO, hypoxia knockout (ERO1 $\left.\alpha^{--}\right)$. 
is a major determinant of how hypoxia impacts cancer progression. Further screening of these proteins revealed that ERO1 $\alpha$ was associated with a particularly poor prognosis and displayed a high meta $\mathrm{z}$ score irrespective of serum availability. We therefore analyzed the expression of ERO1 $\alpha$ in relevant GEO datasets, which confirmed that ERO1 $\alpha$ is induced by hypoxia stress across a range of pancreatic cell lines. These analyses also indicated that ERO1 $\alpha$ is expressed at elevated levels in pancreatic cancers relative to adjacent healthy tissues from the same patient, and that high tumor expression of this enzyme is significantly correlated with short survival duration.

Previous studies have implicated ERO $1 \alpha$ in a range of different cancer types, with current evidence suggesting potential roles in cancer cell invasion of healthy tissues, acquisition of chemoresistant properties, and promotion of angiogenesis [39]. Recent data have also suggested that ERO1 $\alpha$-mediated protein folding is required for the generation of myeloid-derived suppressor cells that protect tumors against immune destruction [40]. In order to test the function of ERO1 $\alpha$ in pancreatic cancer cells, we used a CRISPR/Cas9 approach to delete the corresponding gene and assessed the impact on oncogenic potential in a range of different assays. While ERO $1 \alpha-\mathrm{KO}$ pancreatic cancer cells were morphologically indistinguishable from their wild-type counterparts, tumor proliferation and colony-forming potential were significantly reduced in the absence of this enzyme. Similarly, when we assessed the motility of ERO1 $\alpha-\mathrm{KO}$ tumor cells using in vitro wound healing assays, we observed a marked reduction in migratory potential compared with WT clones. Since ERO1 $\alpha$ enzyme activity is known to generate reactive oxygen species (ROS) which directly regulate the hypoxia response through transcription factor HIF-1 $\alpha$, we next assessed whether ROS generation might underpin the influence of ERO1 $\alpha$ on pancreatic cancer progression. Using DCFDA assays to quantify ROS levels in hypoxic tumor cells, we observed that ERO1 $\alpha-\mathrm{KO}$ clones displayed a significant reduction in ROS generation relative to WT clones. Accordingly, when WT or ERO1 $\alpha-\mathrm{KO}$ cancer cells were injected into BALB/c nu/nu mice, the enzymedeficient tumors failed to develop whereas wild-type cells were highly tumorigenic in vivo. These data are consistent with a previous report that under hypoxic conditions, ERO1 $\alpha$ can also support the development of colorectal cancer by mediating formation of disulfide bonds that activate integrin signaling and modulate expression of EMT markers [41]. Further research will now be required to determine whether ERO1 $\alpha$ also impacts on other pathways such as PI3K-AktmTOR signalling which are frequently activated in pancreatic cancer and known to modulate cell proliferation, protein production, genomic stability, cellular metabolism, and metastatic potential.

Taken together, these data indicate that a combination of microenvironmental hypoxia and restricted blood/nutrient supply trigger pancreatic cancer cell translation of a range of different proteins that act to increase malignancy and are associated with poor clinical outcome. In particular, the oxidizing enzyme ERO1 $\alpha$ is predominantly activated only under abnormal conditions such as hypoxia, which perhaps explains the marked induction of this protein in oxygen-starved tumors. Consistent with this concept, our data confirmed that ERO1 $\alpha$-deficient pancreatic cancer cells displayed negligible ability to form tumors in vivo, thus implicating ERO1 $\alpha$ as a potential novel target for cancer therapy in human patients. Given that ERO1 $\alpha$ function appears less critical under steadystate conditions, it is also possible that therapeutic disruption of this enzyme may succeed in limiting tumor growth and metastasis without significantly damaging healthy cells and tissues. Further investigations will now be required to assess this possibility. Collectively, the findings of this systematic study using pSILAC-based quantitative proteomics reveal that tumor hypoxia induces active translation of a range of critical proteins that are associated with poor prognosis in human cancer patients. Specifically, our data reveal that the oxidoreductase enzyme ERO1 $\alpha$ is a major proliferation regulator in pancreatic cancer cells both in vitro and in vivo, hence this protein may constitute a useful diagnostic marker of tumor progression and possible new therapeutic target in pancreatic malignancy. Further study will now be necessary to understand the precise role of ERO1 $\alpha$ within the tumor microenvironment, determine how this enzyme influences ECM remodelling, and assess potential associations with tumor progression via conditional knockout/overexpression in xenograft and genetically engineered mouse models.

\section{MATERIALS AND METHODS}

\section{Cell culture}

Pancreatic cancer cells of human (MIAPaCa-2) or mouse origin (TGP47) were purchased from the American Type Culture Collection (Manassas, VA, USA) and cultured in Dulbecco's Modified Eagle's Medium (DMEM) (Biowest, France) or a mixture of DMEM and Ham's F12 medium (1:1) supplemented with 10\% foetal bovine serum (FBS) (Gibco, USA) and 1\% Penicillin/ Streptomycin (Naclai-Teqsue, Japan) in a humidified incubator at $37^{\circ} \mathrm{C}$ with $5 \% \mathrm{CO}_{2}$. For serum starvation experiments, the cells were washed three times in $1 \times \mathrm{PBS}$ before incubating in FBS-free media for $24 \mathrm{~h}$. For hypoxia experiments, cells were subjected to low-oxygen culture $\left(<0.1 \% \mathrm{O}_{2}, 5 \% \mathrm{CO}_{2}, 95 \% \mathrm{~N}_{2}\right)$ in a hypoxia chamber for $24 \mathrm{~h}$. Cell lysates were subsequently obtained for protein and gene expression analyses. Cell proliferation was measured using MTT assays as previously described [42].

\section{pSILAC labeling and proteomic sample preparation}

MIAPaCa-2 cells were initially grown for $24 \mathrm{~h}$ in 'light' culture medium (containing unlabelled $146 \mathrm{mg} / \mathrm{l}$ ${ }^{12} \mathrm{C}_{6},{ }^{14} \mathrm{~N}_{2}$-L-Lysine and $84 \mathrm{mg} / 1{ }^{12} \mathrm{C}_{6},{ }^{14} \mathrm{~N}_{2}$-L-Arginine), 
then switched onto 'heavy' medium (containing labelled $146 \mathrm{mg} / 1^{13} \mathrm{C}_{6},{ }^{15} \mathrm{~N}_{2}$-D-Lysine and $84 \mathrm{mg} / 1{ }^{13} \mathrm{C}_{6},{ }^{15} \mathrm{~N}_{2}$-DArginine) and cultured for a further $24 \mathrm{~h}$ under normoxic or hypoxic conditions in the presence or absence of FBS ( $n=2$ independent biological replicates). Cells were then washed with cold PBS and lysed using $8 \mathrm{M}$ urea buffer containing cOmplete ${ }^{\mathrm{TM}}$ EASYpack protease inhibitor cocktail (Sigma Aldrich, USA). In-solution digestion was performed as previously described [26]. Extracted peptides were subjected to fractionation on an XBridge ${ }^{\mathrm{TM}} \mathrm{BEH} \mathrm{C} 18$ column (4.6 × $250 \mathrm{~mm}$; Waters Corporation, Milford, MA, USA) and analyzed by liquid chromatography-tandem mass spectrometry (LC-MS/MS).

Peptides were separated and analyzed on a Dionex Ultimate 3000 RSLCnano system coupled to a Q-Exactive Hybrid Quadrupole-Orbitrap mass spectrometer (Thermo Fisher Scientific Inc, Germany). Separation was performed on a Dionex EASY-Spray $75 \mu \mathrm{m} \times 10 \mathrm{~cm}$ column packed with PepMap C18 $3 \mu \mathrm{m}, 100 \mathrm{~A}^{\circ}$ (ThermoFisher Scientific Inc. Germany) using solvent A ( $0.1 \%$ formic acid in $99.9 \%$ water) and solvent $\mathrm{B}(0.1 \%$ formic acid in $90 \% \mathrm{ACN})$ at flow rate of $300 \mathrm{nl} / \mathrm{min}$ with a $60 \mathrm{~min}$ gradient. Peptides were subsequently analyzed using the Q-exactive MS with an EASY nanospray source (Thermo Fisher Scientific Inc, Germany) at an electrospray potential of $1.5 \mathrm{kV}$. A full MS scan $(350-1,600 \mathrm{~m} / \mathrm{z}$ range) was acquired at a resolution of 70,000 at m/z 200 and a maximum ion accumulation time of $100 \mathrm{~ms}$. Dynamic exclusion was set as $15 \mathrm{~s}$. The resolution of high energy collisional dissociation (HCD) spectra was set to 17,500 at $\mathrm{m} / \mathrm{z} 200$. The automatic gain control settings of the full MS and MS2 scans were 3E6 and 2E5, respectively. The 10 most intense ions above a 2,000-count threshold were selected for HCD fragmentation, with a maximum ion accumulation time of $100 \mathrm{~ms}$. An isolation width of 2 was used for MS2. Single and unassigned charged ions were excluded from MS/MS. For HCD, the normalized collision energy was set to $28 \%$. The underfill ratio was defined as $0.2 \%$.

Protein identification and quantitation were performed by processing the raw data from three replicates using Protein Discoverer (PD) software version 2.2 (Thermo Scientific Inc. Germany). The MS/MS spectra were deisotoped and deconvoluted using the MS2 spectrum processor node in PD. Mascot and Sequest HT were used in parallel and the data compared against a protein sequence file from the UniProt human database (downloaded on 06 Feb 2017, 1,586,248 sequences, $61,972,042$ residues). For searches using both engines, maximum missed cleavage sites per protein was set at 2 , with precursor and fragment ions mass tolerance set at $10 \mathrm{ppm}$ and $0.02 \mathrm{Da}$ respectively. Carbamidomethylation (C) was set as a fixed/static modification. SILAC_R6 (R)/13C(6), SILAC_K8 (K)/13C(6)15N(2), acetylation (Protein N-term), deamidation (NQ) and Oxidation (M) were set as dynamic/variable modifications in both searches. A protein group list was generated from
PD 2.2 software and the list was filtered to exclude contaminating proteins. Only proteins with $q$-value $<0.01$ $(<1 \% \mathrm{FDR})$ as determined by percolator and detected in both replicates were used for further analysis. The mass spectrometry proteomics data have been deposited with the ProteomeXchange Consortium via the PRIDE partner repository under dataset identifier PXD014087.

\section{Western blot}

Cells were washed twice in cold PBS and lysed in RIPA buffer $(0.1 \%$ SDS, $1 \%$ NP-40, $1 \%$ sodium deoxycholate, $150 \mathrm{mM} \mathrm{NaCl}, 1 \mathrm{mM}$ EDTA, and $50 \mathrm{Mm}$ Tris- $\mathrm{HCl} \mathrm{pH} 7.4$, with cOmplete ${ }^{\mathrm{TM}}$ EASYpack protease and phosphatase inhibitors) (Sigma-Aldrich, USA). Cell lysates were subjected to western blotting using the following primary antibodies: anti-ERO1 $\alpha$ (CST), antiHIF-1 $\alpha$ (CST), anti-PDL1 (Abcam), anti-NFIL3 (CST), anti-PHD2 (CST), and anti-E-CAD (BD Bioscience). The loading control was beta-actin (1:5000) (EMD Millipore, USA). Proteins bound by each antibody were visualized using SuperSignal ${ }^{\mathrm{TM}}$ West Pico Chemiluminescence kit (Thermo Fisher Scientific, USA).

\section{RNA isolation and qPCR}

Total RNA was isolated using Nucleospin RNA II kits (Macherey-Nagel GmbH, Germany). Quantitative PCR (qPCR) reactions were performed using the CFX Connect ${ }^{\mathrm{TM}}$ Real-Time PCR Detection System (Bio-Rad Laboratories, Inc.) with KAPA SYBR ${ }^{\circledR}$ FAST qPCR Master mix. Actin was used as an internal control. The primer sequences used for $\mathrm{qPCR}$ are provided in Supplementary Table 1.

\section{Bioinformatic analysis}

The pSILAC protocol allows newly synthesized proteins incorporating heavy $(\mathrm{H})$ arginine and lysine to be distinguished from pre-existing proteins that include only light (L) arginine and lysine residues. Change in pSILAC $\mathrm{H} / \mathrm{L}$ ratio under low-oxygen conditions can therefore be used to determine the impact of hypoxia on tumor cell protein expression activity. Proteins that were actively translated in response to hypoxia either in the presence of serum (HS/NS $>1.5)$ or under serum-free conditions $(\mathrm{HSF} / \mathrm{NSF}>1.5)(p<=0.001)$ were shortlisted for further analysis. Gene ontology and pathway analyses were performed using Functional Annotation (FunRich) [43]. Prediction of Clinical Outcomes from Genomic profiles (PRECOG) and Gene Expression Omnibus (GEO) web tools were used to correlate the pSILAC proteomic data with clinical pancreatic tumor gene expression profiles in order to identify hypoxia-inducible proteins associated with poor prognosis $[44,45]$. Hypoxia-induced proteins that also displayed upregulated gene expression in cancer cells as 
reported in the GEO database were identified as potential targets. These targets were then further analyzed using PRECOG to query associations between gene expression profiles and real-world patient outcomes. Potential targets associated with poor prognosis were identified by PRECOG meta $\mathrm{z}$ score. ERO1 $\alpha$ displayed one of the highest meta $\mathrm{z}$ scores in the dataset and was therefore followed-up in subsequent functional studies. Datasets GSE15471, GSE78229, GSE67549 and GSE28735 reporting the results of pancreatic cancer microarrays in the NCBI GEO database (https://www.ncbi.nlm.nih.gov/geo/) were analyzed to confirm differential ERO1 $\alpha$ expression [46-48].

\section{CRISPR/Cas9 deletion of ERO1a}

All CRISPR gRNA were computationally designed using CHOPCHOP V.2 software (Harvard, USA) to calculate 'on target' score and predicted Cas9 cleavage efficiency using a range of different algorithms (Benchling, San Francisco, CA, USA). Three gRNA were designed (Supplementary Table 3), and target sequences were cloned into lentiCRISPR v2 plasmids (Addgene plasmid \# 52961) as described previously [49].

\section{Colony formation and wound-healing assays}

Colony formation assays were performed as previously described using a total of 200 cells/chamber seeded into six-well plates and cultured in DMEM [50]. To quantify migratory potential, cells were spread and cultured until confluence, then scratched using a $200 \mu \mathrm{l}$ pipette tip before washing and incubating in fresh serumfree medium. After $24 \mathrm{~h}$ culture, scratch dimensions were analyzed using an optical microscope [51].

\section{Intracellular ROS detection}

Intracellular ROS analysis was performed as previously described [52]. Briefly, cells were incubated with $10 \mu \mathrm{M}$ DCFDA in culture media for $1 \mathrm{~h}$ at $30^{\circ} \mathrm{C}$ before harvesting, then washed twice in ice-cold PBS and examined under a fluorescent microscope $(\lambda$ ex $=495 \mathrm{~nm}$ $\lambda \mathrm{em}=530 \mathrm{~nm}$ ) to identify green fluorescence generated by ROS production.

\section{Xenografted tumor development assay}

All animal studies were approved and conducted in compliance with the guidelines of the Institutional Animal Care and Use Committee (IACUC) of Nanyang Technological University. Ncr nude mice (males aged 7 weeks) were obtained from InVivos Pte, Ltd (Singapore). For tumor formation studies, mice were administered $3 \times 10^{6}$ MIAPaCa-2-Con cells $(n=6)$ or MIAPaCa-2-ERO1 $\alpha^{-/-}$ (KO) cells injected subcutaneously into the neck area and tumor size was monitored by caliper measurement. Mice were euthanized when tumor size exceeded $2000 \mathrm{~mm}^{3}$.

\section{Statistical analysis}

Statistical analysis was performed using GraphPad Prism 6.0 software (GraphPad Softwares Inc., La Jolla, CA, USA). Differences between variables were assessed using Student's paired $t$-test, and $P<0.05$ was considered statistically significant. FunRich tool provided $p$-values for each ontology enrichment score. GEO datasets and PRECOG tool enabled statistical analysis of overall survival and $\mathrm{z}$ scores for the highand low-risk groups.

\section{Author contributions}

N.G. designed and performed experiments, analyzed data, and wrote the paper; J.E.P mentored and performed experiments, S.W.T analyzed data; J.K.L, O.L.K, and N.M. contributed reagents and resources, and S.S.K. conceived and designed the project, supervised and revised the manuscript. All co-authors contributed to the revision of the manuscript.

\section{Data availability}

Data Depository: LC-MS/MS raw data from the pulsed-SILAC experiments and results of the protein and peptide identification and quantification in PD2.2 have been deposited with the ProteomeXchange Consortium via the PRIDE [53] partner repository under dataset identifier PXD014087. The raw data and search results can be accessed using the following login to the PRIDE data depository. Project Name: Proteomics analysis of pancreatic cancer cell line (MiaPaCa-2). Project accession: PXD014087.

\section{CONFLICTS OF INTEREST}

There is no conflicts of interest.

\section{FUNDING}

This work is in part supported by the Singapore Ministry of Education (MOE2016-T2-2-018 and MOE2018-T1-001-078) and Singapore National Medical Research Council (NMRC/OFIRG/0003/2016).

\section{REFERENCES}

1. Miller KD, Siegel RL, Lin CC, Mariotto AB, Kramer JL, Rowland JH, Stein KD, Alteri R, Jemal A. Cancer treatment and survivorship statistics, 2016. CA Cancer J Clin. 2016; 66:271-89. https://doi.org/10.3322/caac.21349. [PubMed]

2. Siegel RL, Miller KD, Jemal A. Cancer statistics, 2019. CA Cancer J Clin. 2019; 69:7-34. https://doi.org/10.3322/ caac.21551. [PubMed] 
3. Hussain SP. Pancreatic Cancer: Current Progress and Future Challenges. Int J Biol Sci. 2016; 12:270-2. https://doi. org/10.7150/ijbs.14950. [PubMed]

4. Benzel J, Fendrich V. Chemoprevention and Treatment of Pancreatic Cancer: Update and Review of the Literature. Digestion. 2018; 97:275-87. https://doi.org/10.1159/000485741. [PubMed]

5. McGuigan A, Kelly P, Turkington RC, Jones C, Coleman HG, McCain RS. Pancreatic cancer: A review of clinical diagnosis, epidemiology, treatment and outcomes. World J Gastroenterol. 2018; 24:4846-61. https://doi.org/10.3748/ wig.v24.i43.4846. [ubMed]

6. Saad AM, Turk T, Al-Husseini MJ, Abdel-Rahman O. Trends in pancreatic adenocarcinoma incidence and mortality in the United States in the last four decades; a SEER-based study. BMC Cancer. 2018; 18:688. https://doi. org/10.1186/s12885-018-4610-4. [ubMed]

7. Rawla P, Sunkara T, Gaduputi V. Epidemiology of Pancreatic Cancer: Global Trends, Etiology and Risk Factors. World J Oncol. 2019; 10:10-27. https://doi.org/10.14740/wjon1166. [PubMed]

8. Wu W, He X, Yang L, Wang Q, Bian X, Ye J, Li Y, Li L. Rising trends in pancreatic cancer incidence and mortality in 2000-2014. Clin Epidemiol. 2018; 10:789-97. https:// doi.org/10.2147/CLEP.S160018. [PubMed]

9. Herreros-Villanueva M, Bujanda L. Non-invasive biomarkers in pancreatic cancer diagnosis: what we need versus what we have. Ann Transl Med. 2016; 4:134. https:// doi.org/10.21037/atm.2016.03.44. [PubMed]

10. Swords DS, Firpo MA, Scaife CL, Mulvihill SJ. Biomarkers in pancreatic adenocarcinoma: current perspectives. Onco Targets Ther. 2016; 9:7459-67. https://doi.org/10.2147/ OTT.S100510. [PubMed]

11. Clarke EG, Cowan EC. The nurse in ophthalmic research. Trans Ophthalmol Soc U K. 1976; 96:454. [PubMed]

12. Erkan M, Kurtoglu M, Kleeff J. The role of hypoxia in pancreatic cancer: a potential therapeutic target? Expert Rev Gastroenterol Hepatol. 2016; 10:301-16. https://doi.org/10. 1586/17474124.2016.1117386. [PubMed]

13. Semenza GL. Involvement of hypoxia-inducible factor 1 in human cancer. Intern Med. 2002; 41:79-83. https://doi. org/10.2169/internalmedicine.41.79. [PubMed]

14. Spivak-Kroizman TR, Hostetter G, Posner R, Aziz M, Hu C, Demeure MJ, Von Hoff D, Hingorani SR, Palculict TB, Izzo J, Kiriakova GM, Abdelmelek M, Bartholomeusz G, et al. Hypoxia triggers hedgehog-mediated tumor-stromal interactions in pancreatic cancer. Cancer Res. 2013; 73:3235-47. https://doi.org/10.1158/0008-5472.CAN-111433. [PubMed]

15. Park JE, Tan HS, Datta A, Lai RC, Zhang H, Meng W, Lim SK, Sze SK. Hypoxic tumor cell modulates its microenvironment to enhance angiogenic and metastatic potential by secretion of proteins and exosomes. Mol Cell Proteomics. 2010; 9:1085-99. https://doi.org/10.1074/mcp. M900381-MCP200. [PubMed]
16. Sipos B, Weber D, Ungefroren H, Kalthoff H, Zuhlsdorff A, Luther C, Torok V, Kloppel G. Vascular endothelial growth factor mediated angiogenic potential of pancreatic ductal carcinomas enhanced by hypoxia: an in vitro and in vivo study. Int J Cancer. 2002; 102:592-600. https://doi. org/10.1002/ijc.10753. [PubMed]

17. Liao D, Johnson RS. Hypoxia: a key regulator of angiogenesis in cancer. Cancer Metastasis Rev. 2007; 26:281-90. https:// doi.org/10.1007/s10555-007-9066-y. [PubMed]

18. Krock BL, Skuli N, Simon MC. Hypoxia-induced angiogenesis: good and evil. Genes Cancer. 2011; 2:111733. https://doi.org/10.1177/1947601911423654. [PubMed]

19. Yeo CD, Kang N, Choi SY, Kim BN, Park CK, Kim JW, Kim YK, Kim SJ. The role of hypoxia on the acquisition of epithelial-mesenchymal transition and cancer stemness: a possible link to epigenetic regulation. Korean J Intern Med. 2017; 32:589-99. https://doi.org/10.3904/kjim.2016.302. [PubMed]

20. Zhang Y, Weinberg RA. Epithelial-to-mesenchymal transition in cancer: complexity and opportunities. Front Med. 2018; 12:361-73. https://doi.org/10.1007/s11684-018-0656-6. [PubMed]

21. Maeda K, Ding Q, Yoshimitsu M, Kuwahata T, Miyazaki Y, Tsukasa K, Hayashi T, Shinchi H, Natsugoe S, Takao S. CD133 Modulate HIF-1alpha Expression under Hypoxia in EMT Phenotype Pancreatic Cancer Stem-Like Cells. Int J Mol Sci. 2016; 17. https://doi.org/10.3390/ijms17071025. [PubMed]

22. Yan Q, Chen P, Wang S, Liu N, Zhao P, Gu A. Association between HIF-1alpha C1772T/G1790A polymorphisms and cancer susceptibility: an updated systematic review and meta-analysis based on 40 case-control studies. BMC Cancer. 2014; 14:950. https://doi.org/10.1186/1471-240714-950. [PubMed]

23. Cohen R, Neuzillet C, Tijeras-Raballand A, Faivre S, de Gramont A, Raymond E. Targeting cancer cell metabolism in pancreatic adenocarcinoma. Oncotarget. 2015; 6:1683247. https://doi.org/10.18632/oncotarget.4160. [PubMed]

24. Wu CY, Tsai YP, Wu MZ, Teng SC, Wu KJ. Epigenetic reprogramming and post-transcriptional regulation during the epithelial-mesenchymal transition. Trends Genet. 2012; 28:454-63. https://doi.org/10.1016/j.tig.2012.05.005. [PubMed]

25. Kleppe A, Albregtsen F, Vlatkovic L, Pradhan M, Nielsen B, Hveem TS, Askautrud HA, Kristensen GB, Nesbakken A, Trovik J, Waehre H, Tomlinson I, Shepherd NA, et al. Chromatin organisation and cancer prognosis: a pancancer study. Lancet Oncol. 2018; 19:356-69. https://doi. org/10.1016/S1470-2045(17)30899-9. [PubMed]

26. Dutta B, Yan R, Lim SK, Tam JP, Sze SK. Quantitative profiling of chromatome dynamics reveals a novel role for HP1BP3 in hypoxia-induced oncogenesis. Mol Cell Proteomics. 2014; 13:3236-49. https://doi.org/10.1074/ mcp.M114.038232. [PubMed] 
27. Daniel SK, Sullivan KM, Labadie KP, Pillarisetty VG. Hypoxia as a barrier to immunotherapy in pancreatic adenocarcinoma. Clin Transl Med. 2019; 8:10. https://doi. org/10.1186/s40169-019-0226-9. [PubMed]

28. Gentles AJ, Newman AM, Liu CL, Bratman SV, Feng W, Kim D, Nair VS, Xu Y, Khuong A, Hoang CD, Diehn M, West RB, Plevritis SK, et al. The prognostic landscape of genes and infiltrating immune cells across human cancers. Nat Med. 2015; 21:938-45. https://doi.org/10.1038/nm.3909. [PubMed]

29. Fierro-Monti I, Racle J, Hernandez C, Waridel P, Hatzimanikatis V, Quadroni M. A novel pulse-chase SILAC strategy measures changes in protein decay and synthesis rates induced by perturbation of proteostasis with an Hsp90 inhibitor. PLoS One. 2013; 8:e80423. https://doi. org/10.1371/journal.pone.0080423. [PubMed]

30. Liu TY, Huang HH, Wheeler D, Xu Y, Wells JA, Song YS, Wiita AP. Time-Resolved Proteomics Extends Ribosome Profiling-Based Measurements of Protein Synthesis Dynamics. Cell Syst. 2017; 4:636-44 e9. https://doi. org/10.1016/j.cels.2017.05.001. [PubMed]

31. Riddle SR, Ahmad A, Ahmad S, Deeb SS, Malkki M, Schneider BK, Allen CB, White CW. Hypoxia induces hexokinase II gene expression in human lung cell line A549. Am J Physiol Lung Cell Mol Physiol. 2000; 278:L407-16. https://doi.org/10.1152/ajplung.2000.278.2.L407. [PubMed]

32. Cangul H. Hypoxia upregulates the expression of the NDRG1 gene leading to its overexpression in various human cancers. BMC Genet. 2004; 5:27. https://doi. org/10.1186/1471-2156-5-27. [PubMed]

33. Barrett T, Wilhite SE, Ledoux P, Evangelista C, Kim IF, Tomashevsky M, Marshall KA, Phillippy KH, Sherman PM, Holko M, Yefanov A, Lee H, Zhang N, et al. NCBI GEO: archive for functional genomics data sets--update. Nucleic Acids Res. 2013; 41:D991-5. https://doi.org/10.1093/nar/ gks1193. [PubMed]

34. Harris AL. Hypoxia--a key regulatory factor in tumour growth. Nat Rev Cancer. 2002; 2:38-47. https://doi. org/10.1038/nrc704. [PubMed]

35. Petrova V, Annicchiarico-Petruzzelli M, Melino G, Amelio I. The hypoxic tumour microenvironment. Oncogenesis. 2018; 7:10. https://doi.org/10.1038/s41389-017-0011-9. [PubMed]

36. Goda N, Ryan HE, Khadivi B, McNulty W, Rickert RC, Johnson RS. Hypoxia-inducible factor 1alpha is essential for cell cycle arrest during hypoxia. Mol Cell Biol. 2003; 23:359-69. https://doi.org/10.1128/mcb.23.1.359-369.2003. [PubMed]

37. Bayer C, Vaupel P. Acute versus chronic hypoxia in tumors: Controversial data concerning time frames and biological consequences. Strahlenther Onkol. 2012; 188:616-27. https://doi.org/10.1007/s00066-012-0085-4. [PubMed]

38. Moore LM, England A, Ehrlich BE, Rimm DL. Calcium Sensor, NCS-1, Promotes Tumor Aggressiveness and Predicts Patient Survival. Mol Cancer Res. 2017; 15:942-
52. $\quad$ https://doi.org/10.1158/1541-7786.MCR-16-0408. [PubMed]

39. Seol SY, Kim C, Lim JY, Yoon SO, Hong SW, Kim JW, Choi SH, Cho JY. Overexpression of Endoplasmic Reticulum Oxidoreductin 1-alpha (ERO1L) Is Associated with Poor Prognosis of Gastric Cancer. Cancer Res Treat. 2016; 48:1196-209. https://doi.org/10.4143/crt.2015.189. [PubMed]

40. Tanaka T, Kajiwara T, Torigoe T, Okamoto Y, Sato N, Tamura Y. Cancer-associated oxidoreductase ERO1alpha drives the production of tumor-promoting myeloidderived suppressor cells via oxidative protein folding. J Immunol. 2015; 194:2004-10. https://doi.org/10.4049/ jimmunol.1402538. [PubMed]

41. Takei N, Yoneda A, Sakai-Sawada K, Kosaka M, Minomi K, Tamura Y. Hypoxia-inducible EROlalpha promotes cancer progression through modulation of integrin-betal modification and signalling in HCT116 colorectal cancer cells. Sci Rep. 2017; 7:9389. https://doi.org/10.1038/ s41598-017-09976-7. [PubMed]

42. Mosmann T. Rapid colorimetric assay for cellular growth and survival: application to proliferation and cytotoxicity assays. J Immunol Methods. 1983; 65:55-63. https://doi. org/10.1016/0022-1759(83)90303-4. [PubMed]

43. Pathan M, Keerthikumar S, Ang CS, Gangoda L, Quek CY, Williamson NA, Mouradov D, Sieber OM, Simpson RJ, Salim A, Bacic A, Hill AF, Stroud DA, et al. FunRich: An open access standalone functional enrichment and interaction network analysis tool. Proteomics. 2015; 15:2597-601. https://doi.org/10.1002/pmic.201400515. [PubMed]

44. Toro-Dominguez D, Martorell-Marugan J, LopezDominguez R, Garcia-Moreno A, Gonzalez-Rumayor V, Alarcon-Riquelme ME, Carmona-Saez P. ImaGEO: integrative gene expression meta-analysis from GEO database. Bioinformatics. 2019; 35:880-2. https://doi. org/10.1093/bioinformatics/bty721. [PubMed]

45. Fernandez-Ricaud L, Kourtchenko O, Zackrisson M, Warringer J, Blomberg A. PRECOG: a tool for automated extraction and visualization of fitness components in microbial growth phenomics. BMC Bioinformatics. 2016; 17:249. https://doi.org/10.1186/s12859-016-1134-2. [PubMed]

46. Badea L, Herlea V, Dima SO, Dumitrascu T, Popescu I. Combined gene expression analysis of whole-tissue and microdissected pancreatic ductal adenocarcinoma identifies genes specifically overexpressed in tumor epithelia. Hepatogastroenterology. 2008; 55:2016-27. [PubMed]

47. Wang J, Yang S, He P, Schetter AJ, Gaedcke J, Ghadimi BM, Ried T, Yfantis HG, Lee DH, Gaida MM, Hanna N, Alexander HR, Hussain SP. Endothelial Nitric Oxide Synthase Traffic Inducer (NOSTRIN) is a Negative Regulator of Disease Aggressiveness in Pancreatic Cancer. Clin Cancer Res. 2016; 22:5992-6001. https://doi. org/10.1158/1078-0432.CCR-16-0511. [PubMed] 
48. Zhang G, Schetter A, He P, Funamizu N, Gaedcke J, Ghadimi BM, Ried T, Hassan R, Yfantis HG, Lee DH, Lacy C, Maitra A, Hanna N, et al. DPEP1 inhibits tumor cell invasiveness, enhances chemosensitivity and predicts clinical outcome in pancreatic ductal adenocarcinoma. PLoS One. 2012; 7:e31507. https://doi.org/10.1371/journal. pone.0031507. [ [PubMed]

49. Ran FA, Hsu PD, Wright J, Agarwala V, Scott DA, Zhang F. Genome engineering using the CRISPR-Cas9 system. Nat Protoc. 2013; 8:2281-308. https://doi.org/10.1038/ nprot.2013.143. [PubMed]

50. Rafehi H, Orlowski C, Georgiadis GT, Ververis K, El-Osta A, Karagiannis TC. Clonogenic assay: adherent cells. J Vis Exp. 2011; 2573. https://doi.org/10.3791/2573. [

51. Liang CC, Park AY, Guan JL. In vitro scratch assay: a convenient and inexpensive method for analysis of cell migration in vitro. Nat Protoc. 2007; 2:329-33. https://doi. org/10.1038/nprot.2007.30. [PubMed]

52. Eruslanov E, Kusmartsev S. Identification of ROS using oxidized DCFDA and flow-cytometry. Methods Mol Biol. 2010; 594:57-72. https://doi.org/10.1007/978-1-60761-411-1_4. [PubMed]

53. Perez-Riverol Y, Csordas A, Bai J, Bernal-Llinares M, Hewapathirana S, Kundu DJ, Inuganti A, Griss J, Mayer G, Eisenacher M, Perez E, Uszkoreit J, Pfeuffer J, et al. The PRIDE database and related tools and resources in 2019: improving support for quantification data. Nucleic Acids Res. 2019; 47:D442-D50. https://doi.org/10.1093/nar/gky1106. [PubMed] 